\section{De arte(sanías) y etnias: Cestería Kaingang, producción y significado}

Fernanda Machado Dill ${ }^{(1)}$ y

Margarita Barretto ${ }^{(2)}$

Resumen: Las artesanías Kaingang son el principal elemento de subsistencia, sustentabilidad ambiental y afirmación cultural de la comunidad indígena Aldeia Kondá (Chapecó, Santa Catarina, Brasil). Visitas exploratorias, historia oral y observación participante fueron las estrategias de investigación. La producción de canastos Kaingang garantiza una fuente ambientalmente sostenible de renta para las familias, y de expresión artística, permitiendo momentos de convivencia intergeneracional, lo que contribuye sobremanera para la continuidad cultural.

Palabras clave: pueblo Kaingang - artesanía tradicional - arte indígena - sostenibilidad ambiental - afirmación cultural.

[Resúmenes en inglés y portugués en las páginas 114-115]

(1) Margarita Barretto es Doctora en Educación con post doctorado en Antropología Social. Tiene curso de grado y especialización en Museología; curso de grado en Turismo, y especialización en Metodología de la Enseñanza.

Es profesora visitante en la Universidad Federal de Santa Catarina, investigadora nivel 1C del CNPq (Consejo Nacional de Investigación) de Brasil, donde también fue consejera a nivel nacional. Conduce actualmente una investigación en las misiones jesuíticas de San Ignacio Mini (Argentina), San Miguel das Missões (Brasil) y Calera de las Huérfanas (Uruguay). Es autora de veinte libros, capítulos de libros y obras colectivas, en Argentina, Brasil y España, donde también ha publicado artículos científicos y es miembro del consejo editorial de revistas científicas.

(2) Fernanda Machado Dill es Doctora en Arquitectura y Urbanismo con post doctorado en Proceso en Arquitectura y Urbanismo. Tiene curso de grado en Diseño de producto y en Arquitectura y Urbanismo. Actualmente, es profesora interina en la Universidad Federal de Santa Catarina.

Conduce actualmente una investigación sobre la relación entre cultura y espacio en las comunidades indígenas Kaingang y un estudio sobre análisis socioespacial en las primeras etapas del diseño en arquitectura y urbanismo. 


\section{Introducción}

La cultura material producida por las poblaciones originarias del territorio brasileño es un elemento fundamental, tanto para la afirmación de las especificidades étnicas de las mismas con relación a las sociedades que las rodean, indígenas o no, como para la continuidad de la afirmación cultural de las propias comunidades, ya que los saberes tradicionales pasan de generación en generación. A partir del momento en que se establecieron relaciones con grupos étnicos no indígenas, predominantemente de origen europeo, los artefactos producidos pasaron a representar, además de lo anteriormente expresado, una posibilidad de subsistencia, puesto que en la sociedad capitalista la artesanía puede rendir económicamente permitiendo obtener recursos para la misma.

Este artículo considera el papel de la artesanía Kaingang como protagonista de la continuidad cultural de las familias de Aldea Kondá (Chapecó, Santa Catarina, Brasil) y de las relaciones que se construyeron entre los indígenas y la ciudad de Chapecó a partir de la venta de la cestería tradicional en esta última.

El territorio oeste del estado de Santa Catarina está marcado por un largo proceso de masacre y expropiación de tierras indígenas durante el siglo XIX. En el siglo XX las comunidades indígenas sufrieron, primero, los procesos de colonización y, posteriormente, los vinculados a la urbanización, que hicieron que estos pueblos precisaran adaptarse constantemente, para poder simplemente vivir en su propio suelo.

La comunidad de Aldea Kondá sigue su trayectoria histórica par i pasu con esta sucesión de acciones estatales dentro del contexto regional, que obligaron a una adaptación forzada de los indígenas en lo que atañe a su cultura, a la manera de educar a sus niños, al uso de su lengua materna y, también, a su producción artesanal.

\section{La investigación}

Teniendo en cuenta la complejidad de analizar la cultura de un grupo, esta investigación adoptó un enfoque cualitativo, que permite que la imaginación y la creatividad lleven a proponer nuevas perspectivas de trabajo (Yazigi, 2005). De acuerdo con Minayo (2001), la investigación cualitativa trabaja con el universo de significados, motivos, aspiraciones, creencias, valores y actitudes, lo que corresponde a un análisis más profundo de las relaciones, procesos y fenómenos, que no pueden ser reducidos a la combinación de variables. Es un tipo de investigación que no tiene como objetivo la representatividad numérica sino la comprensión, en profundidad, de un grupo social y de sus relaciones con el lugar en que vive.

La aproximación cualitativa permitió diseñar la investigación de modo que se pudieran usar y relacionar diferentes métodos o procedimientos de análisis, resultando en un proceso interdisciplinar que busca, en la antropología, la historia y la psicología ambiental las bases teóricas para observar, describir, caracterizar y analizar las artesanías producidas por el Pueblo Kaingang, y relacionarlas con el contexto sociocultural de la comunidad y la ciudad en que están insertos. 
Con referencia a los procedimientos investigativos, además del relevamiento bibliográfico se procedió a visitas exploratorias, se obtuvieron relatos de historia oral y se realizaron visitas para observación participante.

Las visitas exploratorias constituyen la primera aproximación y pueden ser registradas mediante dibujos, notas y fotografías (Reinghhantz et al, 2008). Son la base de este tipo de investigación y, de acuerdo con Theodorson y Theodorson (1970) tienen un carácter preliminar para familiarizar al investigador con su objeto de estudio. En este caso se realizaron tres visitas exploratorias a Aldeia Kondá con el objetivo de conocer a los artesanos que allí viven y tomar contacto con sus bases culturales y con el modo Kaingang de vivir y de hacer artesanías.

La perspectiva de dar igual valor a las fuentes escritas y a las orales y el deseo de escuchar lo que los indígenas tienen para decir de sí mismos, de su comunidad, del saber tradicional y del lugar adonde viven justifica el uso de historia oral en esta investigación, sobre todo teniendo en cuenta la representatividad de la tradición oral entre los Kaingang. La historia oral se vuelve fundamental para entender su modo de vivir y contribuir para tener una visión más concreta de la dinámica del funcionamiento y de la trayectoria del grupo social estudiado. La historia oral es siempre un procedimiento que crea nuevas fuentes para la investigación histórica, crea documentos a partir de los relatos obtenidos sistemáticamente con supuestos explícitos (Lozano, 2002).

La observación participante parte de la premisa de que es posible una mayor y mejor aprehensión de un contexto social específico si el observador puede hacer una inmersión, pasar a ser un miembro del grupo social investigado. De acuerdo con Mann, la observación participante es "un intento de colocar el observador y el observado de un mismo lado, donde el observador es un miembro del grupo que puede vivir lo mismo que el grupo y trabajar dentro de su sistema de referencia" (Mann, 1970, p. 96). Solo entonces se puede comprender la relación, en lo cotidiano, entre la artesanía y la cultura Kaingang así como los significados que los productores de esa cultura le confieren.

Como proponen Marconi y Lakatos (2003), el objetivo inicial del investigador debe ser ganar la confianza del grupo, sin ocultar el objetivo de su misión; hacer que sus integrantes entiendan la importancia de la investigación. Por tal motivo, la etapa de observación participante se llevó a cabo después de la etapa exploratoria, en la que se había ya generado una aproximación entre investigador y comunidad.

El período de permanencia más significativo en la comunidad, que al mismo tiempo fue el más prolongado, coincidió con los preparativos para las actividades de la semana cultural Kaingang, en los meses de abril de 2018 y de 2019. Se eligió ese período en función de la concentración de actividades culturales tradicionales, de la intensificación de la producción de artesanías y de la preparación de las comunidades para las actividades conmemorativas asociadas a la festividad y de la afluencia de no indígenas a las aldeas, hecho que permitió la ampliación de los diálogos interculturales. 


\section{El Pueblo Kaingang}

El Pueblo Kaingang es uno de los 305 pueblos indígenas de Brasil. Desde antes de la delimitación de las fronteras de los estados brasileños, viven en las regiones sur y sureste (estados de San Pablo, Paraná, Santa Catalina y Rio Grande del Sur), como ilustra la Figura $1, y$ constituyen a la mayor población indígena del sur del país, con más de sesenta mil personas (Brighenti, 2012).

La composición de la Figura 1 destaca la presencia del pueblo Kaingang en la región e ilustra su movilidad espacial, que se observa hasta hoy. Las áreas de influencia dibujadas están relacionadas a la noción de territorio y a la relación de este pueblo con la tierra, relación esta que se construye de forma diferente entre ellos que en la cultura occidental en general. También la práctica de visitas a los parientes hace que familias e individuos migren entre las comunidades fácilmente.

Para los pueblos indígenas Kaingang la relación establecida con la tierra se sostiene en la reciprocidad y en el bienestar. La tierra se presenta, tradicionalmente no apenas como un medio de subsistencia sino que representa el soporte de la vida social (Tommasino, 2000). La floresta permite la caza y la recolección, brinda el espacio y el material para las viviendas, así como la extracción de la materia prima para sus artesanías y, sobre todo, representa la morada de los espíritus. Es también de la tierra que vienen los alimentos y los remedios, es por donde las comunidades trillan sus caminos y, por eso, tiene tanta importancia para el modo de vivir Kaingang (ibidem).

La tierra para ellos era proveedora de vida y no de lucro, y por ello no podría, o al menos no debería ser parcelada con el único fin de obtener ventajas en lo financiero.

Los Kaingang, lo mismo que otros grupos Jê, se estructuran a partir de una organización social dualista, patrilineal, exogámica y matrilocal (Tommasino y Fernandes, 2001).

Se trata de dos grupos de linajes de parentesco -transmitidos por el padre-, donde las alianzas matrimoniales siempre se dan entre individuos que pertenecen a las mitades opuestas y en las cuales, después del casamiento, el novio pasa a vivir con los padres de la novia.

Las mitades creadoras da la sociedad reciben los nombres de los héroes mitológicos Kamé y Kairú. En el mito de origen recogido por Telêmaco Borba (1908) se halla una versión de la cosmología dualista Kaingang, según la cual Kamé y Kairú provocan no solo divisiones entre los hombres sino entre los demás seres y elementos de la naturaleza, como ilustrado en la Figura 2.

Según la tradición Kaingang, el Sol es Kamé y la Luna, Kairú. El pino es Kamé, el cedro, Kairú, el lagarto es Kamé y el mono es Kairú y así sucesivamente (Borba, 1908) división que tiene como base la noción de complementariedad entre las mitades ${ }^{1}$, que valoriza la belleza existente en la composición entre las diferencias de los opuestos.

En el día a día, la ideología Kaingang enfatiza que la relación entre los opuestos o "contrarios" es ideal y armoniosa, mientras que las relaciones entre los miembros de la misma mitad, es considerada conflictiva. En todas las circunstancias de la vida se insiste en el intercambio entre los que son diferentes.

Para que los remedios de plantas sean más eficaces, deben combinar una planta Kamé y otra Kairú. La relación de intercambio entre las mitades es permanente. Se casan en la mitad opuesta y entierran los muertos de la otra mitad (Veiga, 2004, p. 66) 


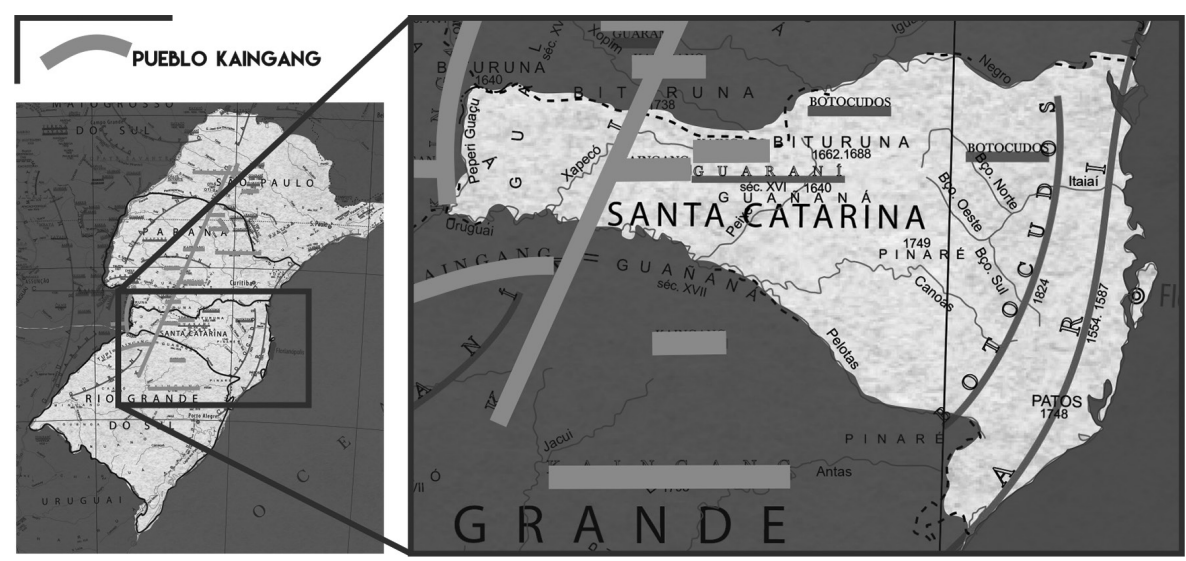

1

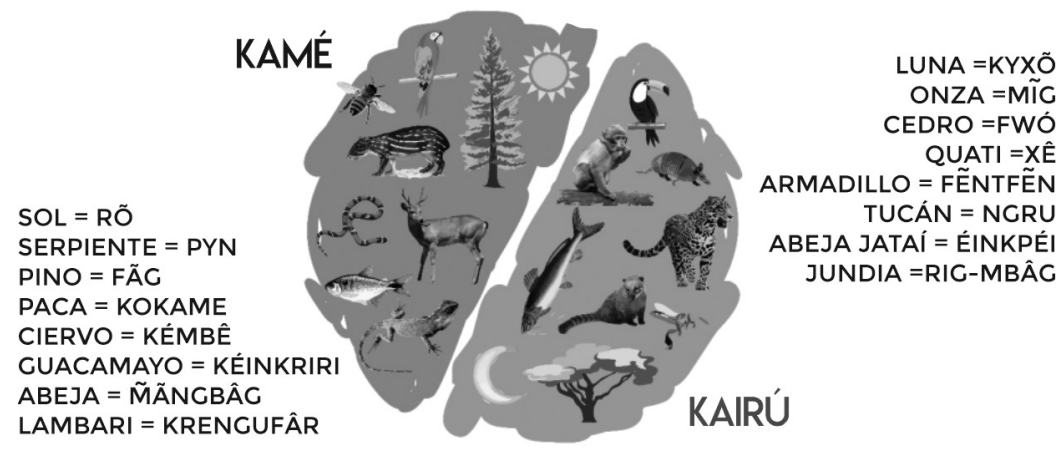

2

Figura 1. Localización de las poblaciones indígenas con destaque para el Pueblo Kaingang. Fuente: Elaborado por una de las autoras con base al Mapa Etno-Histórico de Brasil y regiones adyacentes, de Curt Nimuendajú de 1944 (IBGE, 1981). Figura 2. División de los seres de la naturaleza Kamé e Kairú. Fuente: Elaborado por una de las autoras en base a Borba (1908) y Veiga (1994). 
Además de que poseen características físicas disímiles, los miembros de las mitades se diferencian por medio de las marcas $\left(r a^{2}\right)$ como se ve en la Figura 3.

Se observa en la figura que los Kamé se representaban por marcas alargadas (téi) y rayas verticales, y los Kairú tenían una marca redonda (rór) (Nimuendajú, 1913).

Las subdivisiones de los grupos también pueden ser identificadas por las diferentes marcas: los Wónhetky son representados por líneas curvas y los Votor por círculos.

Cada mitad tiene su pintura. Los Kamé tienen la marca alargada -rá téi ou rá joj-y los Kairú la marca redonda -rá ror ou rá kutu. Algunos Kamé tienen dos rayas (rá táktei). Los Wonhétky tienen líneas curvas que salen de los costados de la boca en dirección a las orejas. La marca redonda de los Kairú son puntos, uno o tres, en la frente y en las mejillas. Los votor tienen círculos que se hacen con un sello confeccionado con tacuara (Tommasino y Rezende, 2000, p. 8).

Los principios socio cosmológicos dualistas tradicionales Kaingang ejercen influencia sobre la estructura social basada en la articulación de unidades territorialmente localizadas, formadas por familias entrelazadas que dividen responsabilidades ceremoniales, sociales, educacionales, económicas y políticas (D’Angelis y Veiga, 2003). Estos principios de complementariedad observados en la estructura social y en las ocupaciones territoriales Kaingang son comunicados, también, a través del sistema de representaciones visuales presente en el grafismo y replicado en otras manifestaciones materiales, tales como la artesanía, que es para ellos un importante símbolo de diferenciación cultural.

La comprensión de los significados del grafismo Kaingang contribuye a la relación establecida entre este grupo y los colores y formas que los representan. Por ello se considera que las manifestaciones estéticas indígenas son sistemas de representación que procuran explicar cómo la sociedad se piensa a sí misma y piensa al mundo que la rodea, traduciendo esas nociones a nuestro propio sistema cognitivo (Ribeiro, 1986).

El proceso productivo de los canastos artesanales, que abarca desde la recolección del material y su preparación, hasta el resultado final con el grafismo formado por el trenzado, representa la mirada del pueblo Kaingang hacia su propia cultura y hacia el mundo que habita.

Los materiales más utilizados son la tacuara mansa, el tacuaruzú, la liana de guabiroba y la de gambé recogidos en las florestas próximas a las aldeas (Sufiatti, Bernardi y Duarte, 2013). Las tacuaras son cortadas, astilladas y finalmente cortadas en tiras longitudinales bien finas, lo que permitirá su trenzado.

La forma de los canastos, los colores utilizados y el grafismo tienen estrecha relación con la cosmología Kaingang y con las mitades clánicas (Silva, 2001).

La mitad Kamé se representa con una forma alargada, alta, abierta, sin fin y es denominada téi; ya a mitad Kairú se representa con grafismos redondos, cuadrados, romboidales bajos y cerrados, a los que se denomina ror. Algunos grafismos no pueden ser identificados respecto a la dualidad a la que pertenecen porque hay una fusión de los patrones téi y ror, son lo que se denomina ianhiá (marca mezclada) (Sufiatti, Bernardi y Duarte, 2013).

Por lo menos dos categorías pueden ser analizadas para identificar las mitades clánicas en la cestería: la forma del artefacto y el grafismo impreso. A partir de las referencias anteriormente citadas, la Figura 4 ilustra un estudio previo llevado a cabo en algunos ejemplares de artesanía Kaingang. 

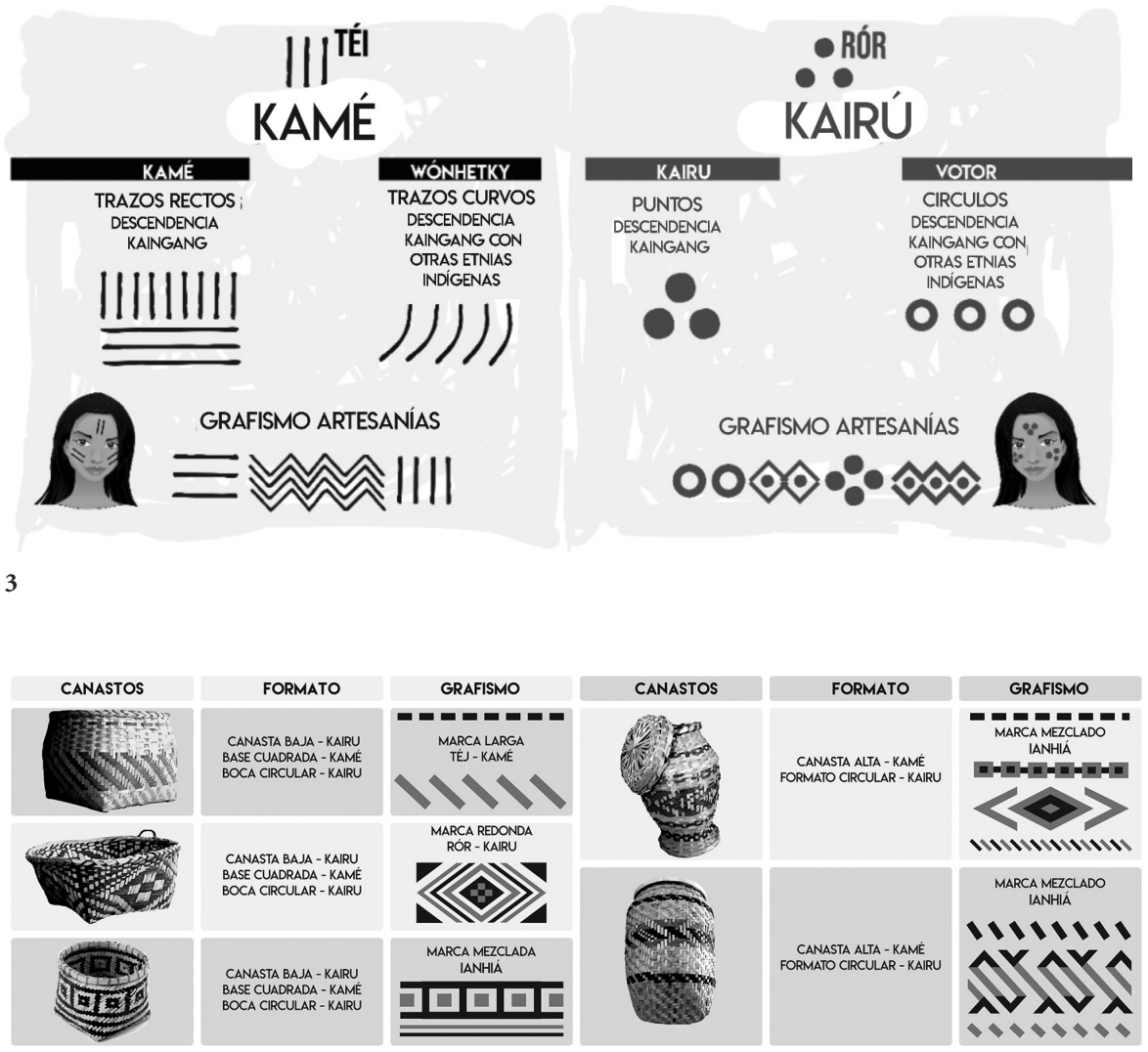

4

Figura 3. Representación de las marcas tribales. Fuente: Elaborado por una de las autoras.

Figura 4. Cestería Kaingang - grafismo y forma. Fuente: elaboración propia.

El sistema de representaciones visuales expresado en la cultura material Kaingang marca la pertenencia de sus integrantes a las mitades tribales y acentúa la necesidad de articulación entre estas partes complementarias para el funcionamiento adecuado de esta sociedad. Cabe todavía destacar que el grafismo impreso en la artesanía es más importante que la forma del objeto, en lo que respecta a la identificación de las mitades, ya que innúmeras veces el uso del artefacto define su forma, siendo entonces utilizado tanto por Kamés cuanto por Kairús. Por otro lado, el grafismo independientemente de la forma del objeto puede identificar la mitad a la que el individuo pertenece. 
Cabe destacar que los grafismos (Kong-gãr) que están presentes en los canastos (kre o tufy), y pintados en los cuerpos y otros objetos como flechas, arcos, calabazas, mortajas, etc. y aún los grafismos presentes en la cultura material prehistórica de las llamadas "tradiciones locales planálticas", son siempre referidos y clasificados por sus interlocutores Kaingang como teí o ror (Silva, 2001, p. 173).

La comunicación en la lengua materna y la confección de artesanías son los símbolos dia$\operatorname{críticos}^{3}$ más importantes para la identidad de este grupo.

\section{Aldeia Kondá: historia, cestería Kaingang y sus significados}

La Reserva Indígena Aldeia Kondá se encuentra en el área rural Linha Água Amarela del municipio de Chapecó y cuenta con una población de más de 900 personas, organizadas en aproximadamente 300 familias, todas Kaingang. Esta área está habitada por los indígenas desde 1999 cuando fue elegida por los propios representantes del Pueblo Kaingang, que en ese entonces vivían en el centro de la ciudad, que era su tierra tradicional.

Registros encontrados en las narrativas del periodista Selistre de Campos ${ }^{4}$ (2004), revelan que después de la emancipación política de Chapecó aumentó la persecución a los indios, impidiéndolos de permanecer en la ciudad:

El gobierno del Estado de Paraná, en 1902, cuando esta zona estaba en su jurisdicción reservó, por decreto, un área de tierra en el ángulo formado por los ríos Chapecó y Chapecozinho, para habitación, uso y disfrute, por parte de los indios que allí estaban localizados desde tiempos inmemoriales (Campos, 2004, p. 61) (Trad. de las autoras).

A partir de 1927, algunas autoridades locales empezaron a solicitar nuevas mediciones de esas áreas de tierra y cuando el espacio ya había pasado a la jurisdicción de Santa Catarina, la posesión de esas tierras pasó a ser reivindicada también por autoridades que actuaban por sus propios intereses (Campos, 2004, p. 61). El SIP (Servicio de Protección a los Indios) pasó a ser, según la prensa de la época, un Servicio de Persecución a los Indios

[...] pero tengan la seguridad de que esto no quedará impune [...] será con nuestra objeción, a través de la prensa y por todos los medios que estén a nuestro alcance. Ese privilegio es un saqueo a los pobres indios y un asalto al patrimonio de la Nación (Campos, 2004, p. 67) (Trad. de las autoras).

A partir de entonces los indígenas, sin protección quedaron a merced de los desmanes del gobierno y de la justicia no indígena, y fueron cada vez más expropiados de sus tierras originales y obligados a "civilizarse", léase adaptarse a la sociedad circundante de los nuevos colonos.

Como consecuencia de ese intento de asimilación forzada, los indígenas sufrieron con enfermedades que aún no conocían, lo que ocasionó, -junto con la usurpación de su de- 
recho a la asistencia de salud- el exterminio de parte de la población Kaingang en aquella época (Campos, 1949).

En un corto período de tiempo, como consecuencia de los procesos colonizadores, y de la llamada "traición del SPI" el territorio indígena, que era inicialmente de 123.000 hectáreas se redujo a apenas 23.000. Luego, con la modernización de la ciudad, se redujo más todavía (Campos, 1949) conduciendo, décadas después a la total extinción del área Kaingang que actualmente hace parte (invisibilizada) del perímetro urbano del municipio de Chapecó. A mediados del siglo XX, con el proceso de construcción de la ciudad, la falta de respeto a los indígenas continuó, así como la expropiación de sus tierras. Según el Reporte de las Familias Kaingang residentes en Chapecó ${ }^{5}$, elaborado en 1998, había en la ciudad una población indígena considerable, constituida principalmente por dos grupos distintos; el primero compuesto por la familias que residían en barrios de la ciudad adaptados a la nueva cultura impuesta por los no indígenas, invisibilizados (Tommasino et al., 1998) y el segundo, más extenso, compuesto por las familias que resistían y establecieron una relación de parentesco con base en la preservación de la cultura y organizaron las aldeas en la ciudad. Según Tommasino (1998) los miembros de este grupo eran más visibles y provocaron reacciones variadas en la población urbana, potenciando los prejuicios contra los indígenas, y rotulándolos como un "problema social".

Esas familias vivían en condiciones extremadamente precarias, sin acceso a saneamiento básico, salud pública (mucho menos privada) o educación. A pesar de ello permanecieron en el local, hablando su lengua materna y confeccionando las artesanías cuya materia prima obtenían después de caminar grandes distancias en el área rural del municipio.

Se cree que una de las principales razones que llevó a la permanencia de esas familias en la región, a pesar de las condiciones antes relatadas, fue la constatación de que allí también vivieron sus antepasados, y el recuerdo de aquellos.

La relación con la ancestralidad indígena vinculada a un territorio específico es un factor constante en este estudio, puesto que para los Kaingang las relaciones de parentesco son centrales así como la propia noción de territorio tradicional.

A continuación podemos ver por ejemplo el barrio Palmital (Figura 5) que ilustra algunos aspectos de las viviendas y de la confección de las artesanías, que eran el principal medio de subsistencia al momento de la investigación.

De acuerdo con el Reporte II, "Elección del área para los Kaingang de Aldeia Kondá (1999)", los indígenas describían la ciudad de Chapecó como siendo su tierra tradicional, en la cual cazaban, colectaban y enterraban a sus muertos. El local central de la tierra de sus abuelos, de acuerdo con los relatos de los ancianos de la comunidad, coincide con el actual centro de la ciudad, y esto revela por qué el municipio continúa siendo territorio tradicional, un lugar donde se dan las relaciones sociales, políticas y cosmológicas fundamentales para el grupo.

En base a los relatos de los ancianos de Aldeia Kondá, se identificaron los lugares simbólicos del pueblo Kaingang en el actual centro de la ciudad. Son ellos el Rio Paso de los Indios, hoy canalizado, invisibilizado por la construcción de la peatonal Benjamin Constant. Sobre el primer gran asentamiento Kaingang están hoy la Catedral y la Plaza Coronel Ernesto Bertaso. Y, finalmente donde estuvo el primer Cementerio Kaingang se sitúa actualmente un importante hotel. 

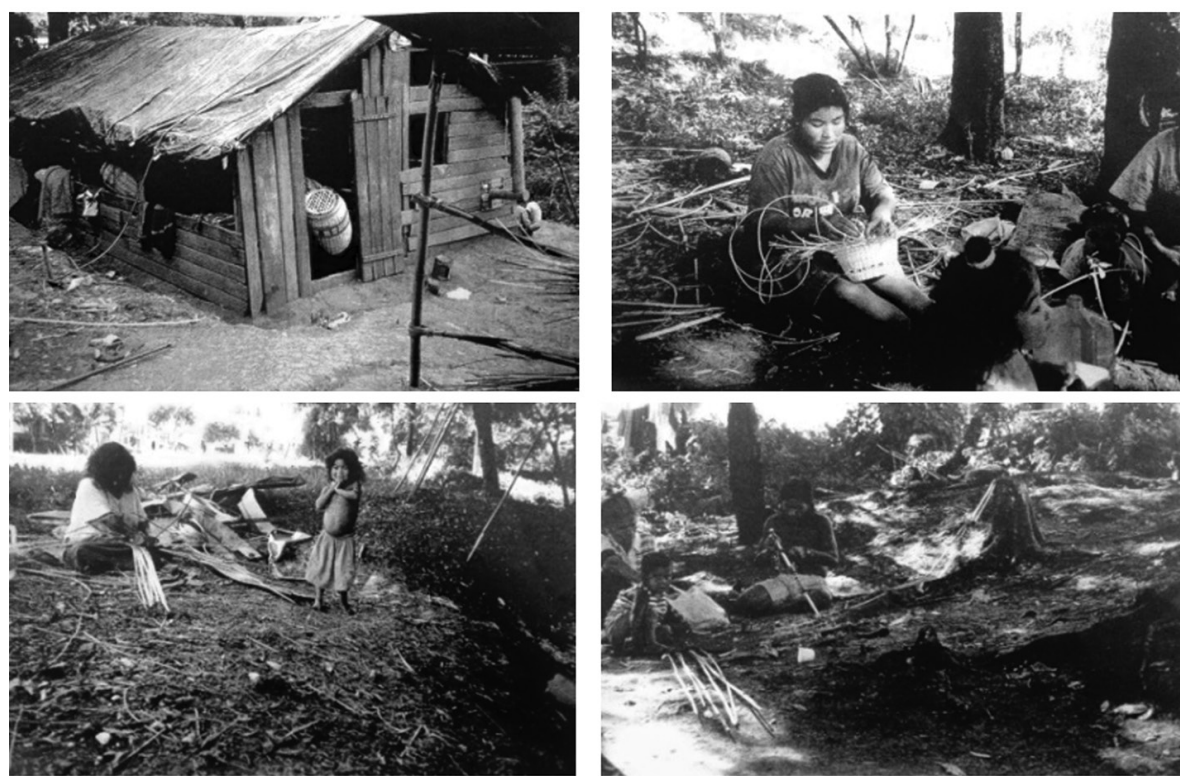

Figura 5. Fotos de Aldeia Kondá en el Barrio Palmital. Fuente: Reporte de las Familias Kaingang en la ciudade de Chapecó, 1998.

Los prejuicios que enfrentaron en la ciudad y la negativa a reconocer el territorio indígena por parte de la sociedad Chapecoense intensificaron las luchas por la conquista de la tierra. Este proceso de resistencia, según los antiguos moradores de Aldeia Kondá aproximó los indígenas, intensificó el uso de la lengua Kaingang, de la producción de artesanías tradicionales y finalmente contribuyó a la afirmación de su identidad cultural.

Actualmente el área ocupada por la comunidad demuestra la posibilidad de regeneración de la naturaleza mediante el manejo sostenible y de la relación de reciprocidad que los habitantes establecen con el medio natural.

Los blancos dicen que queremos la tierra para que todo se transforme en floresta. $Y$ claro, precisamos de floresta. Es de la floresta que sacamos la tacuara para las artesanías, los remedios [...] y las comidas tradicionales. Lo que no está bien es envenenar todo como ellos están haciendo, que uno tiene hasta miedo de pescar y comer porque ellos envenenan el agua.. Cuando vinimos para acá no daba nada, la tierra era pobre, no tenía fuerza, por eso [...] ahora está bien mejor, los animales están volviendo, tenemos hasta lo qué cazar de vez en cuando pero todavía va a demorar para quedar como tiene que ser (Feliciano ${ }^{7}, 2018$ ). 

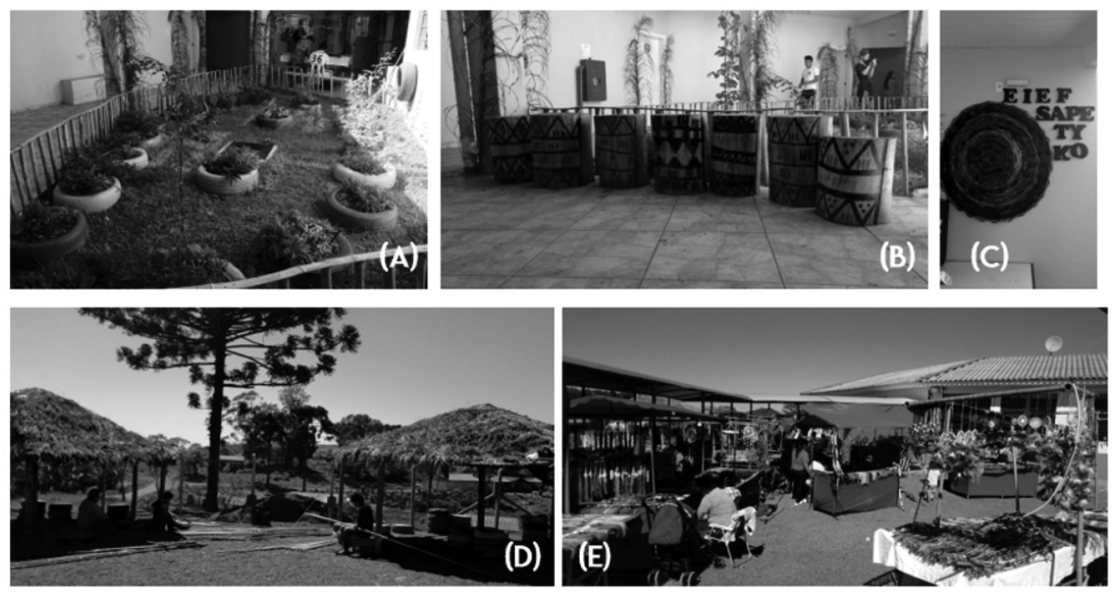

Figura 6. Interior de la Escuela Sape Ty Kó. Fuente: Acervo personal.

Los artesanos indígenas relatan que cuando se mudaron para esa área no encontraron condiciones para cultivar alimentos, ni encontraban la materia prima necesaria para la confección de sus artesanías. No obstante, luego de veinte años retomando el territorio, la floresta y los animales hacen parte del cotidiano de la comunidad y permiten acciones de afirmación cultural intergeneracionales como la caza, la extracción de lianas y de tacuara y la preparación de comidas tradicionales.

Otro lugar preponderante para enseñar artesanías es la escuela, que pasó por modificaciones para que la comunidad pudiera apropiarse de ella, resultando en un espacio de cobijo y afirmación cultural, como se observa en la Figura 6.

La escuela está cercada con bambú (A), los asientos de madera pintados con los grafismos de las mitades tribales Kamé y Kairú (B), las artesanías se exponen en las paredes de la escuela (C), las estructuras externas construidas para dar clases al aire libre y enseñar artesanías (D). La imagen (E) muestra la realización de una de las semanas culturales que trajeron a los demás moradores para la escuela, principalmente a los ancianos y artesanos de la comunidad.

La escuela es, si, un importante espacio de intercambios culturales y de venta de las artesanías, porque es visitada de forma recurrente por estudiantes de escuelas no indígenas y habitantes de las comunidades vecinas. Pero el lugar donde el saber hacer tradicional emerge con más fuerza y más frecuentemente es en las residencias, en las casas de los abuelos. En esos espacios, alrededor del fuego (Figura 7) los ancianos enseñan a los más jóvenes cómo trenzar la tacuara, y cuentan, en idioma Kaingang, las historias de sus antepasados. 

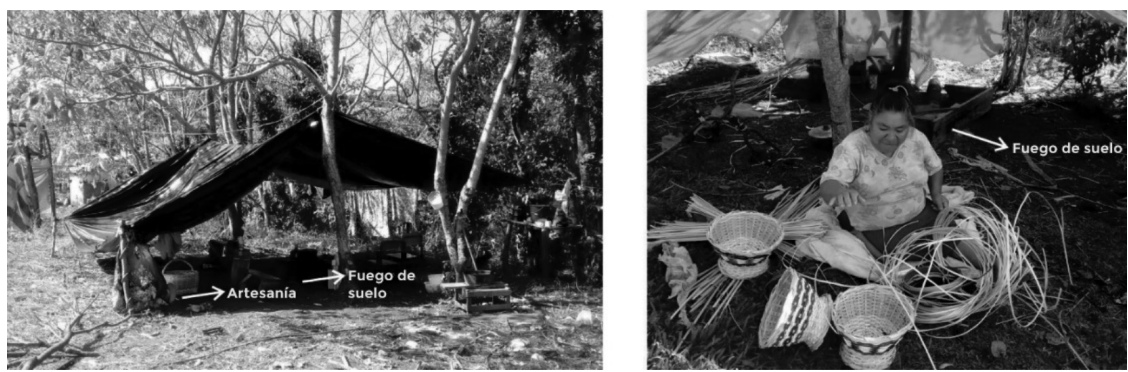

7
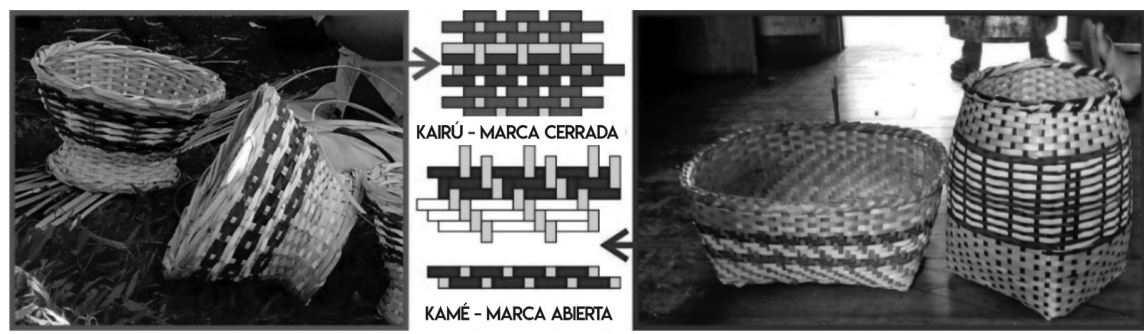

8

Figura 7. Estructura auxiliar. Fuente: Acervo propio. Figura 8. Artesanías de Aldeia Kondá. Fuente: Elaborado por una de las autoras.

En invierno y verano, se observa en la mayor parte de las residencias una estructura externa improvisada con lona (Figura 7) utilizada para confección de artesanías y para abrigar una pequeña fogata alrededor de la cual los viejos cuentan sus historias al anochecer. Es un espacio más para intercambios y convivencia social, ya que estas estructuras están localizadas en el centro de cada núcleo familiar.

En la cultura material existen varias formas de diferenciación de los objetos. Una de ellas es la edad del artesano, considerada "un dato importante porque identifica la variabilidad del artefacto atribuible a factores relacionados al ciclo de vida y al desarrollo personal del productor" (Ribeiro y Ribeiro, 1987, p. 21). Este dato informa lo que fue pasado de una generación para la otra, porque en las sociedades indígenas los niños pasan más tiempo con sus abuelos que con sus padres, recibiendo de los primeros estos conocimientos (Savoro, Mozzato y Nötzold, 2006).

La artesanía (Figura 8) continúa representando la principal fuente de ingresos y tiene, además del componente financiero, el hecho de permitir la diferenciación cultural. "En los canastos están nuestras mitades y nuestra forma de vivir" afirmó el Sr. Augusto, anciano que acompañaba uno de nuestros paseos por la aldea. 
La venta de artesanías -arte indígena- hace que los indios se tengan que desplazar al centro de la ciudad, y por eso muchas veces se planteó que hay una falta de respeto a la comunidad por parte de la sociedad no indígena. Los indígenas quieren reconquistar un espacio digno en la ciudad. "Ellos nos miran de arriba y eso está mal. Aquella tierra toda era nuestra casa!" afirma el Sr. Augusto cuando comenta la forma en que son tratados.

La venta de arte indígena Kaingang en el centro de Chapecó ha provocado discusiones en diversas esferas, dada la amplitud de la cuestión. A pesar de que esta práctica representa el regreso al territorio original y la afirmación cultural Kaingang frente a la sociedad, los indígenas corren riesgos: la violencia en el tránsito, las intemperies (no hay un local adecuado para la comercialización de sus productos) los prejuicios y la falta de respeto de una parte de la población que no los reconoce como locales, a pesar de que la ciudad está llena de símbolos que remiten a la cultura indígena, empezando por el nombre del estadio de fútbol, Arena Kondá, que antes se llamó Estadio Regional Indio Kondá. Otras referencias son el rio Paso de los Indios, los barrios Epafi y Palmital, y otros más que tienen nombres indígenas. En el caso específico de los Kaingang de Aldéia Kondá, la gran mayoría de las 200 familias que integran ese grupo tiene como única fuente de ingresos la comercialización de artesanías por lo que se tienen que desplazar permanentemente al centro para vender las mismas y garantir la supervivencia. En estos desplazamientos es común que los niños acompañen a sus padres, tíos o abuelos y que ayuden a vender las piezas, lo que muchas veces es criticado, pues la población no indígena lo encuadra como una forma de trabajo infantil (MPF, 2019).

Las críticas, no obstante, denotan falta de conocimiento de la realidad socioeconómica de los indígenas de Aldeia Kondá. Es preciso también entender que estos desplazamientos en los territorios que siempre ocuparon constituyen un rasgo distintivo de la cultura y la tradición de los grupos Kaingang del oeste del estado de Santa Catarina.

En 2019 se celebró un acuerdo con la tienda de la Asociación Chapecoense de Fútbol para que ésta comercialice las artesanías producidas en Aldeia Kondá. Esta idea fue propuesta por el Ministerio Público Federal (MPF), y aceptada por la dirigencia del club de fútbol que vio en esta iniciativa una primera forma de retribuir al pueblo Kaingang, inclusive por el uso del nombre del Cacique con que designaron el estadio Arena Condá y de su imagen en la logomarca.

Se cree que la proyección internacional alcanzada por el club pueda también agregar valor a las artesanías que serán comercializadas en su local.

Acciones como esta son importantes dada la falta de información sobre la relevancia de la presencia indígena para la construcción de las ciudades y su derecho a permanecer en su territorio tradicional.

\section{Discusión y consideraciones finales}

Aldéia Kondá es una de las comunidades consideradas más tradicionales inclusive por las otras comunidades de la región, porque todos sus miembros hablan la lengua materna, porque producen artesanías tradicionales y porque valorizan a sus ancianos como sabios. 
Durante nuestra investigación, los líderes expresaron su preocupación con la posible pérdida de los valores tradicionales Kaingang debido a que los niños y adolescentes tienen contacto con la cultura no indígena. Con el uso de celulares y debido a la televisión, muchos aspectos culturales perdieron fuerza y ellos consideran que es obligación de los más antiguos contar las historias del pasado y enseñar las prácticas culturales ancestrales. "Pero no es fácil, los más jóvenes no se interesan por la cultura. Quieren estar en el celular y no en la floresta" (Sr. Augusto, anciano de Aldéia Kondá).

Por otro lado, los profesores entienden que el acceso a las tecnologías puede contribuir a la afirmación de los valores propios, a medida que los alumnos dialogan con otras culturas y reconocen las diferencias.

Entendemos que la cultura material Kaingang es importante para la afirmación de la continuidad cultural de esta comunidad por varias funciones. La primera es el intercambio de experiencias y de conocimientos entre las diferentes generaciones propiciado por el momento en que se enseñan las artesanías. Al explicar cómo se puede trenzar y teñir la tacuara, o como es que los dibujos surgen conforme sea el canasto elaborado, los ancianos destacan la relación de respeto e interdependencia con la naturaleza, la importancia de conocer y respetar las mitades Kamé y Kairú manifestadas en los grafismos, el respeto por el paso del tiempo, la calma para la confección de un canasto bien hecho y tantas otras enseñanzas pasadas, generalmente, en la lengua Kaingang.

A medida que la artesanía se presenta como principal fuente de renta en la comunidad, y también como una forma de arte, la posibilidad de obtener retorno financiero a partir de la comercialización de artefactos cargados de cultura y simbolismo, puede incentivar a los más jóvenes a dedicarse a esta práctica.

Finalmente, se destaca que la presencia indígena para la venta de artesanías en el centro de la ciudad denota una actitud de resistencia y de regreso a su tierra tradicional, expropiada de la comunidad para dar lugar a una ciudad que denotaría "progreso", un "progreso" que invisibiliza a los habitantes primeros y originarios, comunidades que tienen mucho para enseñar sobre todo en lo que respecta a establecer relaciones de equilibrio con la naturaleza y regenerar áreas que la sociedad llamada "civilizada" se ha encargado de destruir.

Mientras los Kaingang estén en el centro de la ciudad vendiendo y exponiendo su arte repleto de colores, formas y significados, permanecen vivos y visibles, en sus territorios de origen, resistiendo a la exclusión de su historia y de su cultura.

\section{Notas}

1. La grafía de las mitades clánicas Kaingang aparece de forma diferente conforme cada investigador. Veiga (1994) escribe Kame y Kahru, Telêmaco Borba escribía Camés y Kayrucrés, Baldus utilizaba la grafía Kadnyerú y Kamé. Estas diferencias se pueden atribuir tanto a variaciones dialectales como a los diferentes períodos de registro. Para este trabajo se optó por la grafía Kamé y Kairú porque es de esta forma que lo escriben las comunidades objeto de esta investigación. Se agregó un acento agudo en Kairú para pronunciarlo de forma correcta en la traducción al español. 
2. La palabra Kaingang Ra designa las marcas tribales y las pinturas corporales características de cada mitad Kamé y Kairú. Es común en las comunidades la expresión "Eg ra” que significa "nuestras marcas".

3. Aspecto complementar que modifica el valor de algún símbolo, en este caso, el idioma como elemento que agrega algo relevante a la construcción cultural.

4. "A Voz de Chapecó", 24 de octubre de 1948, n²06. Acervo del Centro de Memoria de la Uno Chapecó, (CEOM), 2004.

5. El Reporte de identificación de las familias Kaingang que residen en la ciudad de Chapecó, se entregó en marzo de 1998 y fue elaborado a partir de un estudio antropológico solicitado por la FUNAI-ADR de Chapecó. Allí aparece la reivindicación de las familias de Aldeia Kondá (residentes en el Barrio Palmital en aquel momento) pidiendo una tierra adonde vivir de acuerdo con sus costumbres.

6. Reporte II: Elección de área para los Kaingang de Aldeia Kondá. Fue realizado en 1999, para evaluar posibles áreas para ser destinadas a la aldea y elegir una de ellas con la participación de la comunidad indígena.

7. Testimonio de la Sra. Marilene Feliciano, Anciana y partera de la Reserva Indígena Kondá.

\section{Referencias}

Borba, T. (1908). Actualidade indígena. Coritiba: Typ e Lytog a Vapor impressora Paranaense. Brighenti, C. A. (2012). Povos Indígenas em Santa Catarina. Florianópolis: UFSC.

Campos, S. (2004). A voz de Chapecó: Artigo de Antonio Selistre de Campos - 1939-1952. Centro de Memória do Oeste Catarinense (org). Chapecó: Argos.

D'Angelis, W. R. y Veiga, J. (2003). Habitação e Acampamentos Kaingang hoje e no passado. Cadernos do CEOM n.18, 213-242.

Lozano, J. E. (2002). Prática e estilos de pesquisa em história oral contemporânea. In: FERREIRA, Usos e abusos da história oral. Rio de Janeiro: Editora FGV, 5ed, 2002, p. 15-25. Mann, P. H. (1970). Métodos de investigação sociológica. Rio de Janeiro: Zahar.

Marconi, M. y Lakatos, E. M. (2003). Fundamentos de metodologia científica. São Paulo: Atlas. Minayo, M. C. (2001). Pesquisa social: teoria, método e criatividade. Petrópolis: Vozes.

MFP, Ministério Público Federal do Estado de Santa Catarina. (2019). Inquérito Civil n. 1.33.002.000287/2016-27. Disponible en: http://www.mpf.mp.br/sc/sala-de-imprensa/ noticias-sc/2019indigena-artesanato-kaingang-da-aldeia-conda-sera-comercializado -na-loja-da-associacao-chapecoense-de-futebol-1.

Nimuendajú, C. (1913). Etnografia e indigenismo - Sobre os Kaingang, os Afaié-Xavante e os indios do Perá. Campinas: UNICAMP.

Ribeiro, B. G. (1986). A linguagem simbólica da cultura material. Suma Etnológica brasileira V.03 Arte india, 11-27.

Ribeiro, D. y Ribeiro Berta, G. (1987). Suma Etnológica Brasileira. Tecnologia Indígena 2. Rio de Janeiro: FINEP, 2a ${ }^{\text {a }}$ Ed. 
Rheingantz, P. A., et al. (2009). Observando a Qualidade do Lugar: procedimentos para o trabalho de campo. Rio de Janeiro: Faculdade de Arquitetura e Urbanismo, UFRJ.

Savoro, T. D.; Silva, N. M. da.; Nötzold, A. L. V. (2006). Artesanato Kaingang: entre usos e desusos da cultura material. In: Cadernos do CEOM - Ano 19, n. 24 - Cultura Material.

Schid, J. D. (2016). Mulheres Kaingang, seus caminhos, politicas e redes na TI Serrinha. Dissertação de mestrado no Programa de Pós Graduação em Antropologia Social. Florianópolis: UFSC.

Silva, S. B. (2001). Etnoarqueologia dos grafismos "Kaingang": um modelo para a compreensão das sociedades Proto-Jê meridionais. Tese de Doutorado em Arqueologia. São Paulo: FFLCH/USP.

Sufiatti, T.; Bernardi, L. \& Duarte, C. G. (2013). Cestaria e a história de vida dos artesãos indígenas da Terra Indígena Xapecó. In: Revista Latinoamericana de Etnomatemática, 67-98.

Theodorson, G. A. y Theodorson, A. G. (1970). A modern dictionary of sociology. London: Methuen.

Tommasino, K. et al. (1999). Relatório II: Eleição de área para os Kaingang da Aldeia Kondá. Chapecó: FUNAI.

Tommasino, K. (2000). Algumas considerações acerca das exposições proferidas pelos representantes dos povos indígenas no Simpósio As cidades e os povos indígenas: Mitologias e Visões. In: L. T. Mota, As cidades e os povos indígenas: Mitologias e Visões. Maringá: EDUEM. Tommasino, K.(2001). Território e territorialidade Kaingang. Resistência cultural e historicidade de um grupo Jê. In: L. T. MOTA, F. S. NOELLI, E. K. TOMMASINO, Uri e Wãxi - Estudos Interdisciplinares dos Kaingang. (pp. 191-226). Londrina: UEL.

Tommaasino, K. y Rezende, J. F. (2000). Kikikoi - Ritual dos kaingang na área indígena Xapecó/SC: registro áudio-fotográfico do ritual dos mortos. Londrina: Midiograf.

Veiga, J. (2004). Os Kaingáng e Xokléng no panorama dos Povos Jê. LIAMES 4, 59-70.

Veiga, J. (1994). Organização Social e cosmovisão Kaingáng: Uma introdução ao parentesco, casamento e nominação em uma sociedade Jê Meridional. Dissertação de mestrado em Antropologia. Campinas: UNICAMP.

Yázigi, E. (2005). Deixe sua estrela brilhar: criatividade em ciências humanas e no planejamento. São Paulo: CNPQ.

\begin{abstract}
Kaingang handicrafts are the main element of subsistence, environmental sustainability and cultural affirmation of Aldeia Kondá indigenous community (Chapecó, Santa Catarina, Brazil). Exploratory visits, oral history, and participant observation were the research strategies. Kaingang baskets guarantee an environmentally sustainable source of income for families, as well as a way of artistic expression, allowing moments of intergenerational coexistence, which greatly contribute to cultural continuity.
\end{abstract}

Keywords: Kaingang people - traditional handicraft - ethnic arts - environmental susteinabiliby - cultural reassurence. 
Resumo: $\mathrm{O}$ artesanato Kaingang é o principal elemento de subsistência, sustentabilidade ambiental e afirmação cultural da comunidade indígena Aldeia Kondá (Chapecó, Santa Catarina, Brasil). Visitas exploratórias, história oral e observação participante foram as estratégias de pesquisa. A produção das cestas Kaingang garante uma fonte de renda ambientalmente sustentável para as famílias, e também de expressão artística, permitindo momentos de convivência intergeracional, o que muito contribui para a continuidade cultural.

Palavras chave: aldeia Kaingang-artesanato tradicional - arte indigena - sustentabilidade ambiental - afirmação cultural.

[Las traducciones de los abstracts fueron supervisadas por el autor de cada artículo] 